\title{
Phonotactic Knowledge and Lexical-Semantic Processing in One-year-olds: Brain Responses to Words and Nonsense Words in Picture Contexts
}

\author{
Manuela Friedrich and Angela D. Friederici
}

\begin{abstract}
During their first year of life, infants not only acquire probabilistic knowledge about the phonetic, prosodic, and phonotactic organization of their native language, but also begin to establish first lexical-semantic representations. The present study investigated the sensitivity to phonotactic regularities and its impact on semantic processing in 1-yearolds. We applied the method of event-related brain potentials to 12- and 19-month-old children and to an adult control group. While looking at pictures of known objects, subjects listened to spoken nonsense words that were phonotactically legal (pseudowords) or had phonotactically illegal word onsets (nonwords), or to real words that were either congruous or incongruous to the picture contents. In 19-month-olds and in adults, incongruous words and pseudowords, but not nonwords, elicited an N400 known to reflect mechanisms of semantic integration. For congruous words, the N400 was
\end{abstract}

\section{INTRODUCTION}

During their first year of life, infants' speech perception abilities become gradually tuned to the properties of their native language sound structure. This tuning process develops as a result of infants' ongoing experience with their native language input. It is characterized by both an increase in sensitivity to native language contrasts and a decline in sensitivity to foreign language contrasts (Cheour et al., 1998; Kuhl, Williams, Lacerda, Stevens, \& Lindblom, 1992; Best, McRoberts, \& Sithole, 1988; Werker \& Lalonde, 1988; Werker \& Tees, 1984). Infants' tuning to native language sound categories is accompanied by an increase in attentional preference for listening to speech that observes the phonetic, prosodic, and phonotactic organization of their native language (Friederici \& Wessels, 1993; Jusczyk, Cutler, \& Redanz, 1993; Jusczyk, Friederici, Wessels, \& Svenkerud, 1993; for a review, see Jusczyk, 1997). It reflects some familiarity with the regularities of their native language

Max Planck Institute for Human Cognitive and Brain Sciences attenuated by semantic priming. In contrast, 12-month-olds did not show an N400 difference, neither between pseudo- and nonwords nor between incongruous and congruous words. Both 1-year-old groups and adults additionally displayed a lexical priming effect for congruous words, that is, a negativity starting around $100 \mathrm{msec}$ after words onset. One-year-olds, moreover, displayed a phonotactic familiarity effect, that is, a widely distributed negativity starting around $250 \mathrm{msec}$ in 19-month-olds but occurring later in 12-month-olds. The results imply that both lexical priming and phonotactic familiarity already affect the processing of acoustic stimuli in children at 12 months of age. In 19-month-olds, adult-like mechanisms of semantic integration are present in response to phonotactically legal, but not to phonotactically illegal, nonsense words, indicating that children at this age treat pseudowords, but not nonwords, as potential word candidates. sound structure, which facilitates the later process of language acquisition (e.g., infants use their knowledge about phonotactic probabilities to segment the speech stream into single words) (Friederici \& Wessels, 1993).

To comprehend words or to acquire new word meanings, infants must figure out those parts of the acoustic input that potentially represent meaningful words. Moreover, phonological representations must be mapped onto conceptual representations that either are already established or must be constituted on-line from ongoing meaningful contexts. This means that lexical mapping and semantic processing mechanisms must be initiated in response to potential words.

Semantic processing routines are electrophysiologically indicated by the N400, a negative wave that occurs in the event-related brain potential (ERP) of adults at about 400 msec after stimulus onset (Kutas \& Hillyard, 1980; for a review, see Kutas \& Federmeier, 2000). The N400 reflects mechanisms of semantic integration of a stimulus into the current context (Holcomb, 1993) such as semantic integration of a word into its sentence context (e.g., Friederici, Pfeifer, \& Hahne, 1993) or integration of a picture into a picture story (West \& 
Holcomb, 2002). Any stimulus that is semantically unexpected in the current context releases greater N400 amplitudes than a stimulus that is semantically primed or that can otherwise be predicted by the semantic context. In adults, pseudowords (i.e., nonsense words that obey the phonetic, prosodic, and phonotactic rules of a given language) elicit substantial N400 responses, whereas nonwords (i.e., nonsense words that violate the regularities of a language) do not (Bentin, Mouchetant-Rostaing, Giard, Echallier, \& Pernier, 1999; Nobre \& McCarthy, 1994; Holcomb, 1993; Holcomb \& Neville, 1990; Bentin, 1987; Rugg \& Nagy, 1987; Bentin, McCarthy, \& Wood, 1985). Thus, the N400 is assumed to represent a default response (Kutas \& Van Petten, 1994) that is initiated in response to words or other potentially meaningful stimuli such as pictures, pseudopictures, and pseudowords, but not in response to nonwords that do not act as potential referents for meaning.

Adult-like N400 responses on words and pictures have also been reported for children (Hahne, Eckstein, \& Friederici, 2004; Coch, Maron, Wolf, \& Holcomb, 2002; Friederici \& Hahne, 2001; Gonzalez-Garrido et al., 1997; Holcomb, Coffey, \& Neville, 1992; Friedman, Sutton, Putnam, Brown, \& Erlenmeyer-Kimling, 1988). Using slowly spoken words presented in picture contexts, we observed an N400-like response on words even in 19-month-old children (Friedrich \& Friederici, 2004). In this age group, the negative responses in the ERP on words that were incongruous to the pictures reached its maximum at about $600 \mathrm{msec}$, whereas the N400 semantic priming effect, the negativity in the difference between incongruous and congruous words, displayed the strongest effect between 800 and 900 msec.

The ERP response on words and nonsense words presented without meaningful context had already been investigated in children between 1 and 2 years old (Mills et al., 2004; Mills, Coffey-Corina, \& Neville, 1993, 1994; Molfese, Wetzel, \& Gill, 1993; Molfese, 1989, 1990). Molfese and his colleagues (Molfese et al., 1993; Molfese, 1989, 1990) presented children with words that were either known or unknown to the children. A positive-tonegative shift that occurred over frontal and/or temporal brain regions within temporal ranges of 200 to $350 \mathrm{msec}$ differentiated between known and unknown words in 12-, 14-, and 16-month-old children.

In the study of Mills, Coffey-Corina, and Neville (1993), 20-month-old children listened to known words, unknown words, and backward-presented words. Sensitivity to the different word types was indicated by two early negative components that were called N200 and N350. Both components were more pronounced in words children knew than to those they did not know and were nearly absent in response to backwardpresented words. Thus, amplitudes of these early negative components appear to reflect familiarity with native language sounds, which is higher in known than unknown words and absent in backward-presented words that grossly violate phonetic, prosodic, and phonotactic features of a given language. In this study with 20-month-olds, an additional negative response occurred between 600 and $900 \mathrm{msec}$. This later response might indicate the presence of semantic processing routines that are initiated in response to potential words. Although the N600-900 differed with the children's language abilities, it did not vary with word type.

Up to now, the ERP response on nonsense words that are either phonotactically legal or phonotactically illegal has not been examined in children. In the present study, we investigated the sensitivity of 1-year-olds to phonotactic knowledge by measuring their ERP response to nonsense words in picture contexts. Pseudowords that meet phonetic, prosodic, and phonotactic properties of German might represent potential meaningful words that are currently unknown to the children. Nonwords that meet phonetic and prosodic properties but violate phonotactic properties cannot become meaningful words, and thus, do not act as potential words if phonotactic rules of the language are taken into account.

Words or word-like stimuli presented in semantic context are expected to trigger lexical-semantic processing routines reflected in the occurrence of an N400 in the ERP. If these were default responses to any speech input, such mechanisms would already be present at birth. As a default response, one would expect a developmental tuning process that should be reflected in a decline of attempted lexical-semantic processing for stimuli that are unlikely according to the sound organization of the native language. If, in contrast, the N400 is the reflection of lexical-semantic processing routines that mature later, at a time when native language properties are well established, then it should develop in response to potentially meaningful words and should not be applied to other word-like stimuli. In either case, both developmental increase and developmental decrease are assumed to result in an adult-like pattern of initiating $\mathrm{N} 400$ processing mechanisms in response to pseudowords but not to nonwords.

As the paradigm in this study requires that children already know the meaning of the pictured objects, we measured children at an age of 12 and 19 months. This age difference of more than half a year should allow us to, at least partly, access developmental changes in the children's brain activity that are correlated with their increase in phonotactic knowledge of German. The comparison of words that are congruous and words that are incongruous to the pictures are taken as a control condition to test whether the mechanisms reflected in the N400 are already present in both age groups and whether the expected differences between the processing of pseudo- and nonwords are similar to the N400 effect between incongruous and congruous words in topography and timing. 
Because adult ERP differences between pseudo- and nonwords have only been only observed by using either visually presented stimuli (Bentin et al., 1999; Nobre \& McCarthy, 1994) or acoustically presented backward speech for the nonword condition (Holcomb \& Neville, 1990), and because the stimuli we used for the 1-year-olds were spoken much slower than those typically used in N400 studies, we additionally assessed adults with identical stimuli in the same paradigm to directly compare the ERP responses of children and adults.

\section{RESULTS}

\section{Event-related Brain Potentials of 12-month-olds}

Pseudowords versus Nonwords

The ERPs of 12-month-olds on nonsense words (Figure 1, top) were dominated by a frontally distributed sustained positive wave that was split by small negative deflections. Differences between pseudo- and nonwords occurred over the left lateral frontal, left temporal, and slightly over the frontal and central brain regions (see Figure 2, top, for the spatial distribution). They were indicated by a condition main effect in the time window from 800 to $900 \mathrm{msec}$, and by interactions of condition with region from 600 to $900 \mathrm{msec}$ (Table 1A). Analyses of single-electrode sites (Table $1 \mathrm{C}$ ) revealed that during these time windows, the ERP responses on pseudowords were more negative than those of nonwords over the left lateral frontal brain region. In the temporal range from 800 to $900 \mathrm{msec}$, the left temporal, right frontal, and right fronto-central brain regions were also involved in this effect.

\section{Incongruous Words versus Congruous Words}

To investigate whether the observed differences between pseudo- and nonwords might represent an infant-specific N400-like response, we also compared the ERPs for congruous and incongruous words (Figure 3, left). Similar to the responses on nonsense words, the ERPs of 12-month-olds on words were characterized by a frontally distributed slow positive wave with opposite directed peaks. Differences between congruous and incongruous words could be observed even during very early processing stages. Condition main effects, with more negative responses on congruous than incongruous words, were present from 100 to $500 \mathrm{msec}$ (Table 1A,B). Moreover, an interaction of condition with region occurred from 100 to $250 \mathrm{msec}$. Subsequent analyses of single-electrode sites revealed that in this early time window, the effect included only lateral frontal, temporal, frontal, and centro-central brain regions $[F(1,45)=4.6-16.2, p<.05]$. There was no time window in which incongruous words elicited significantly more negative responses than congruous words. Thus, in 12-month-olds, no N400-like effect could be observed between incongruous and congruous words.

\section{Pseudowords versus Congruous Words}

To confirm the absence of an N400 in 12-month-olds, we also compared the ERPs on pseudowords with that on congruous words (Figure 3, right). Again, condition main effects occurred from 100 to $500 \mathrm{msec}$ (Table 1A,B). They were caused by more negative responses on congruous words than on pseudowords. In contrast to the effect observed between congruous and incongruous words, the parietal region was strongly involved during the whole interval in which the effect occurred. In addition, interactions of condition and region were present from 500 to $900 \mathrm{msec}$ as well as from 1000 to 1100 msec. Within these time windows, congruous words also elicited more negative responses than pseudowords but only over parietal and centro-parietal brain regions (Table 1C). That is, although pseudowords elicited more negative responses than nonwords in 12-month-olds, they did not elicit an N400-like response when compared with congruous words.

\section{Event-related Brain Potentials of 19-month-olds}

\section{Pseudowords versus Nonwords}

The ERPs of 19-month-old children on pseudo- and nonwords (Figure 1, middle) also showed a frontally distributed slow positive wave with opposite directed deflections. During long periods, clear differences were present between the responses on pseudo- and nonwords. Condition main effects occurred from 250 to 1200 msec (Table 2A,B). Within each time window, pseudowords elicited more negative responses than nonwords. An interaction of condition with region from 250 to $400 \mathrm{msec}$ and subsequent single site analyses indicated that differences between pseudo- and nonwords started in the left frontal region $[F(1,46)=4.1$, $p<.05]$. Thus, in 19-month-olds, the effect as a whole might be composed of an early left frontal negativity that is already present in 12-month-olds and, possibly, an N400-like negativity (see Figure 2 for the spatial distribution).

\section{Incongruous Words versus Congruous Words}

To interpret the results obtained for pseudo- and nonwords adequately, we also analyzed the responses between congruous and incongruous words. This enables the comparison of the long-lasting negative effect for nonsense words with the spatio-temporal distribution of the N400 difference for words. Similar to 12-month-olds, the ERPs of 19-month-olds revealed very early starting 
Figure 1. ERPs on pseudoand nonwords for 12- and 19-month-olds and adults. Solid lines for phonotactically legal pseudowords and dotted lines for phonotactically illegal nonwords.

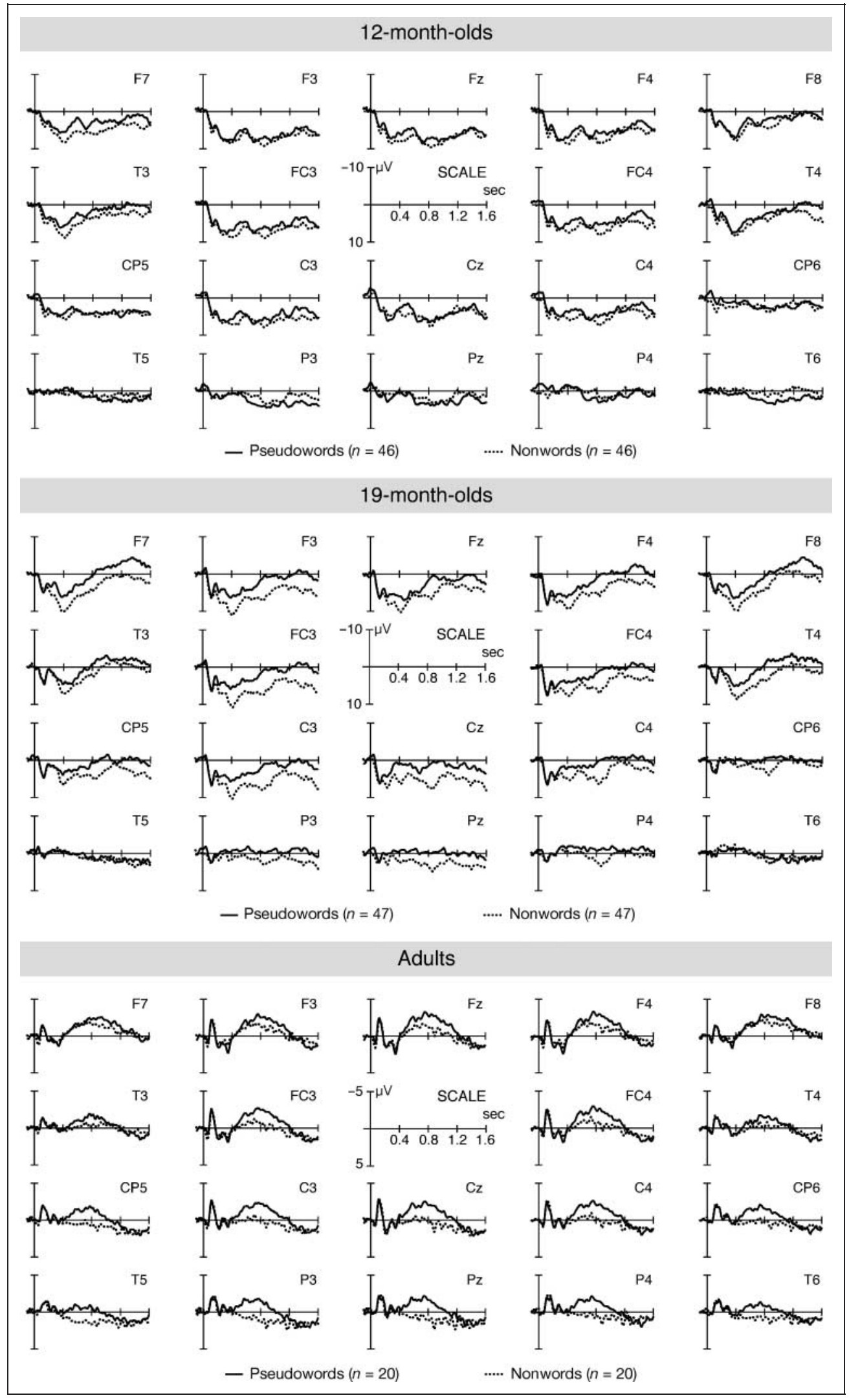




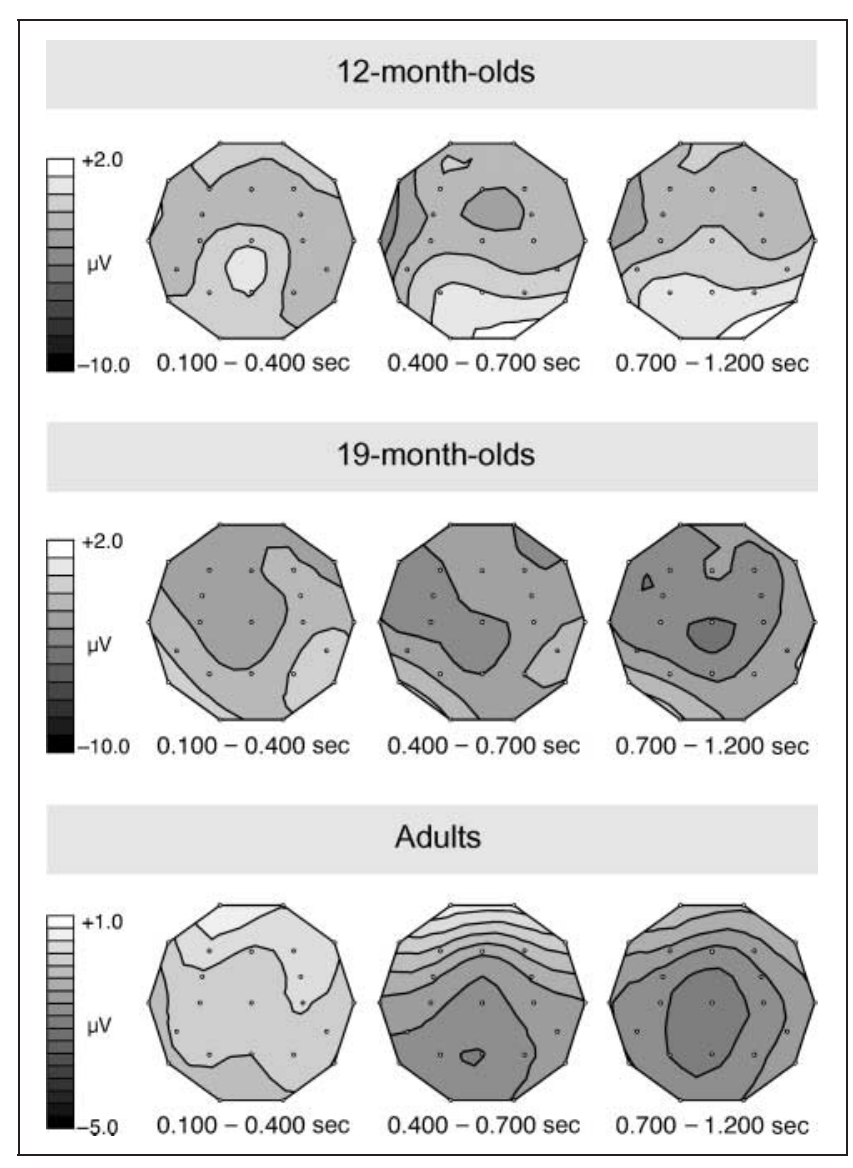

Figure 2. Spatial distribution of the difference between pseudoand nonwords for 12- and 19-month-olds and adults. For electrode positions, see Figure 3.

differences between congruous and incongruous words (Figure 4 , left). Interactions of condition with region were present from 100 to $600 \mathrm{msec}$, from 800 to $1100 \mathrm{msec}$, and over midline sites from 250 to $800 \mathrm{msec}$ (Table 2A,B). Although congruous words elicited more negative responses than incongruous words over left lateral frontal and right frontal brain regions from 100 to $400 \mathrm{msec}$, incongruous words evoked a broadly distributed, more-negative-going potential than congruous words from 400 to $1200 \mathrm{msec}$ (Table 2C). This N400like processing difference also caused condition main effects from 700 to $1200 \mathrm{msec}$ and over midline sites from 500 to $1200 \mathrm{msec}$ (Table 2A,B). The centro-parietal distribution of the N400 semantic incongruity effect is displayed in Figure 6 (left, top).

\section{Pseudowords versus Congruous Words}

As in 19-month-olds, the negative difference wave between pseudo- and nonwords seemed to be caused by the overlap of an N400-like centro-parietal effect with an earlier starting left lateral frontal effect; we also compared the responses on pseudowords to those of congruous words (Figure 4, right). This additional comparison provides more evidence for the attribution of a part of that effect to the N400 and more information about the spatio-temporal distribution of the possible N400 on pseudowords.

Similar to the comparison of the word stimuli, the early, more negative response on congruous words in the lateral frontal and temporal brain region gave rise to both interactions of condition, hemisphere, and region from 100 to $400 \mathrm{msec}$ and a condition main effect from 250 to $400 \mathrm{msec}$ (Table 2A). An interaction of condition with region in the following time window from 400 to 500 msec was caused by a sustained, more negative response for congruous words in the temporal brain region and a concurrent, more negative response for pseudowords in the centro-central region (Table 2C). Stronger negative responses for pseudowords than for congruous words were also observed from 500 to $1000 \mathrm{msec}$ over midline sites and within the temporal ranges from 800 to $1200 \mathrm{msec}$ over parietal, central, temporal, fronto-central, and centro-parietal brain regions (for the spatial distribution, see Figure 6, left, bottom). The distribution of the difference between pseudowords and congruous words and its similarity to the N400 between incongruous and congruous words strongly suggest that it represents an N400-like effect.

\section{Event-related Brain Potentials of Adults}

\section{Pseudowords versus Nonwords}

The adult ERP on nonsense words (Figure 1, bottom) showed the early N1-P2 complex that is typically evoked by auditory stimuli. Within the time range of the N1-P2 as well as within the following small negative-positive wave pattern, there were no apparent differences between the responses on pseudo- and nonwords. Starting at about $400 \mathrm{msec}$, pseudowords elicited stronger negative responses than nonwords, primarily over parietal and central brain regions. This was reflected in condition main effects from 500 to $1200 \mathrm{msec}$ and over midline sites from 400 to $1200 \mathrm{msec}$ (Table 3A,B). Interactions of condition with region that occurred from 400 to $1100 \mathrm{msec}$ indicated the spatial differences in that effect. Analyses of single-electrode sites revealed that the effect started at $400 \mathrm{msec}$ in the centro-central, parieto-central, and left parietal brain region $[F(1,19)=$ $4.4-7.2, p<.05]$ and spread out to other regions at about $500 \mathrm{msec}$. Regions not involved in this effect were the frontal region from 500-800 msec and the temporal region from 900-1100 msec (see Figure 3, bottom, for the spatial distribution).

\section{Incongruous Words versus Congruous Words}

Processing differences between congruous and incongruous words (Figure 5, left) occurred very early, which 
Table 1. Condition Effects of 12-month-olds

A. Within Three-way Condition $\times$ Hemisphere $\times$ Region ANOVAs

\begin{tabular}{|c|c|c|c|c|c|c|}
\hline \multirow[b]{2}{*}{$\begin{array}{l}\text { Time Window } \\
\text { (msec) }\end{array}$} & \multicolumn{2}{|c|}{ Pseudowords vs. Nonwords } & \multicolumn{2}{|c|}{$\begin{array}{l}\text { Incongruous Words vs. } \\
\text { Congruous Words }\end{array}$} & \multicolumn{2}{|c|}{$\begin{array}{l}\text { Pseudowords vs. } \\
\text { Congruous Words }\end{array}$} \\
\hline & $\begin{array}{l}\text { Condition, } \\
F(1,45)\end{array}$ & $\begin{array}{c}\text { Condition } \times \text { Region, } \\
F(6,270)\end{array}$ & $\begin{array}{l}\text { Condition, } \\
F(1,45)\end{array}$ & $\begin{array}{c}\text { Condition } \times \text { Region } \\
F(6,270)\end{array}$ & $\begin{array}{l}\text { Condition, } \\
F(1,45)\end{array}$ & $\begin{array}{c}\text { Condition } \times \text { Region, } \\
F(6,270)\end{array}$ \\
\hline $100-250$ & & & $8.2 * * *$ & $2.5 * *$ & $4.8^{* *}$ & \\
\hline $250-400$ & & & $5.1 * *$ & & $17.6^{* * *}$ & \\
\hline $400-500$ & & & $4.3 * *$ & & $3.9^{*}$ & \\
\hline $500-600$ & & & & & & $3.7 * * *$ \\
\hline $600-700$ & & $3.1 * *$ & & & & $3.6 * *$ \\
\hline $700-800$ & & $3.3^{* *}$ & & & & $2.7 * *$ \\
\hline $800-900$ & $4.5^{* *}$ & $4.2 * * *$ & & & & $4.9 * * *$ \\
\hline \multicolumn{7}{|l|}{$900-1000$} \\
\hline $1000-1100$ & & & & & & $2.7 * *$ \\
\hline $1100-1200$ & & & & & $4.9 * *$ & \\
\hline \multicolumn{7}{|c|}{ B. Within Midline Two-way Condition $\times$ Region ANOVAs } \\
\hline \multirow[b]{2}{*}{$\begin{array}{l}\text { Time Window } \\
(\mathrm{msec})\end{array}$} & \multicolumn{2}{|c|}{ Pseudowords vs. Nonwords } & \multicolumn{2}{|c|}{$\begin{array}{l}\text { Incongruous Words vs. } \\
\text { Congruous Words }\end{array}$} & \multicolumn{2}{|c|}{$\begin{array}{l}\text { Pseudowords vs. } \\
\text { Congruous Words }\end{array}$} \\
\hline & $\begin{array}{l}\text { Condition, } \\
F(1,45)\end{array}$ & $\begin{array}{c}\text { Condition } \times \text { Region, } \\
F(2,90)\end{array}$ & $\begin{array}{l}\text { Condition, } \\
F(1,45)\end{array}$ & $\begin{array}{c}\text { Condition } \times \text { Region, } \\
F(2,90)\end{array}$ & $\begin{array}{l}\text { Condition, } \\
F(1,45)\end{array}$ & $\begin{array}{c}\text { Condition } \times \text { Region, } \\
F(2,90)\end{array}$ \\
\hline $100-250$ & & & $6.0 * *$ & $3.1 *$ & $12.5 * * *$ & \\
\hline $250-400$ & & & $3.0^{*}$ & & $24.5 * * *$ & \\
\hline $400-500$ & & & & & $8.3 * * *$ & \\
\hline $500-600$ & & & & & & $2.5^{*}$ \\
\hline $600-700$ & & & & & $2.9^{*}$ & \\
\hline $700-800$ & & & & & $3.0 *$ & \\
\hline \multicolumn{7}{|l|}{$800-900$} \\
\hline \multicolumn{7}{|l|}{$900-1000$} \\
\hline \multicolumn{7}{|l|}{$1000-1100$} \\
\hline $1100-1200$ & & & & & $4.8^{* *}$ & \\
\hline \multicolumn{7}{|c|}{ C. For Single-electrode Sites Within One-way ANOVAs } \\
\hline $\begin{array}{l}\text { Time Window } \\
(m s e c)\end{array}$ & $\begin{array}{l}\text { Pseudo } \\
\text { F( }\end{array}$ & $\begin{array}{l}\text { words vs. nonwords, } \\
(45)=3.1-12.0\end{array}$ & & & $\begin{array}{r}\text { Pseudoword } \\
F(1,4\end{array}$ & $\begin{array}{l}\text { vs. congruous words, } \\
5)=4.9-12.8\end{array}$ \\
\hline $500-600$ & & & & & $\mathrm{Pz}$ & $3, \mathrm{P} 4, \mathrm{CP} 5 * *$ \\
\hline $600-700$ & F7* & & & & $\mathrm{Pz}$ & $3, \mathrm{P} 4 * *$ \\
\hline $700-800$ & $\mathbf{F} 7 *$ & & & & $\mathrm{Pz}$ & $3, \mathrm{CP} 5 * *$ \\
\hline
\end{tabular}


Table 1. (continued)

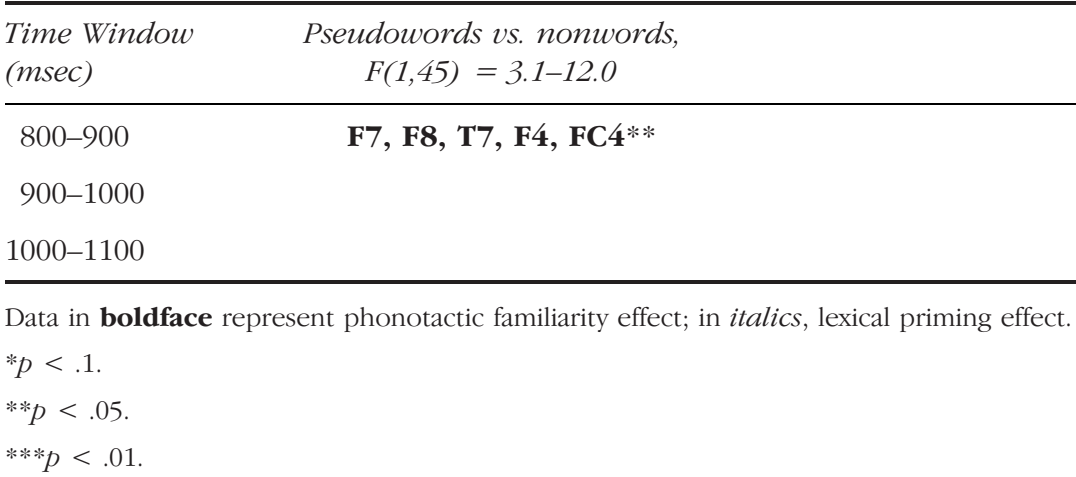

was reflected in a condition main effect from 100$250 \mathrm{msec}$ (Table 3A). Like for 1-year-olds, congruous words evoked more negative responses than incongruous words. In adults, this effect was strongest over the left temporal brain region. Condition main effects that occurred from 250 to $1200 \mathrm{msec}$ indicated that incongruous words elicited a long-lasting, more negative response than congruous words (Table 3A,B). Interactions of condition with region were observed from 250 to $700 \mathrm{msec}$. Moreover, interactions of con- dition with hemisphere were present from 400 to $500 \mathrm{msec}[F(1,19)=7.1, p<.05]$ and from 500 to $600 \mathrm{msec}[F(1,19)=5.6, p<.05]$. Analyses of singleelectrode sites indicated that the early effect from 400-500 msec occurred over the centro-central, centroparietal, right central, right parietal, and right parietocentral regions $[F(1,19)=5.0-31.3 p<.05]$. From 500 to $600 \mathrm{msec}$, all brain regions except the left temporal, and from 600 to $700 \mathrm{msec}$, all except left temporal and left lateral frontal brain regions were involved in the



Figure 3. Comparison of the ERPs of 12-month-old children on incongruous and congruous words (left) and on pseudo- and congruous words (right). 
Table 2. Condition Effects of 19-month-olds

A. Within Three-way Condition $\times$ Hemisphere $\times$ Region ANOVAs

\begin{tabular}{|c|c|c|c|c|c|c|}
\hline \multirow[b]{2}{*}{$\begin{array}{l}\text { Time Window } \\
(\mathrm{msec})\end{array}$} & \multicolumn{2}{|c|}{ Pseudowords vs. Nonwords } & \multicolumn{2}{|c|}{$\begin{array}{l}\text { Incongruous Words vs. } \\
\text { Congruous Words }\end{array}$} & \multicolumn{2}{|c|}{$\begin{array}{l}\text { Pseudowords vs. } \\
\text { Congruous Words }\end{array}$} \\
\hline & $\begin{array}{l}\text { Condition, } \\
F(1,46)\end{array}$ & $\begin{array}{c}\text { Condition } \times \text { Region, } \\
F(2,276)\end{array}$ & $\begin{array}{l}\text { Condition, } \\
F(1,46)\end{array}$ & $\begin{array}{c}\text { Condition } \times \text { Region, } \\
F(2,276)\end{array}$ & $\begin{array}{l}\text { Condition, } \\
F(1,46)\end{array}$ & $\begin{array}{c}\text { Condition } \times \text { Region }, \\
F(2,276)\end{array}$ \\
\hline $100-250$ & & & & $3.2 * *$ & & $(3.9 * * *)$ \\
\hline $250-400$ & $13.5 * * *$ & $3.1 * *$ & & $4.7^{* * *}$ & $5.0^{* *}$ & $\left(4.6^{* * *}\right)$ \\
\hline $400-500$ & $15.6 * * *$ & & & $4.0 * * *$ & & $2.8^{* *}$ \\
\hline $500-600$ & $5.6 * *$ & & & $2.8^{* *}$ & & \\
\hline $600-700$ & $7.8 * * *$ & & & $2.2^{*}$ & & \\
\hline $700-800$ & $15.0^{* * *}$ & & $6.7 * *$ & $2.1^{*}$ & & \\
\hline $800-900$ & $27.2 * * *$ & & $12.7^{* * *}$ & $3.7^{* *}$ & $3.7^{*}$ & $2.7^{* *}$ \\
\hline $900-1000$ & $20.4 * * *$ & & $17.1 * * *$ & $3.3 * *$ & $5.7^{* *}$ & $2.5^{*}$ \\
\hline $1000-1100$ & $7.2^{* *}$ & & $13.0 * * *$ & $2.6^{* *}$ & & $3.3 * *$ \\
\hline $1100-1200$ & $5.2 * *$ & & $8.5 * * *$ & {$[4.6 *]$} & {$[4.5 * *]$} & $2.8^{* *}$ \\
\hline
\end{tabular}

B. Within Midline Two-way Condition $\times$ Region ANOVAs

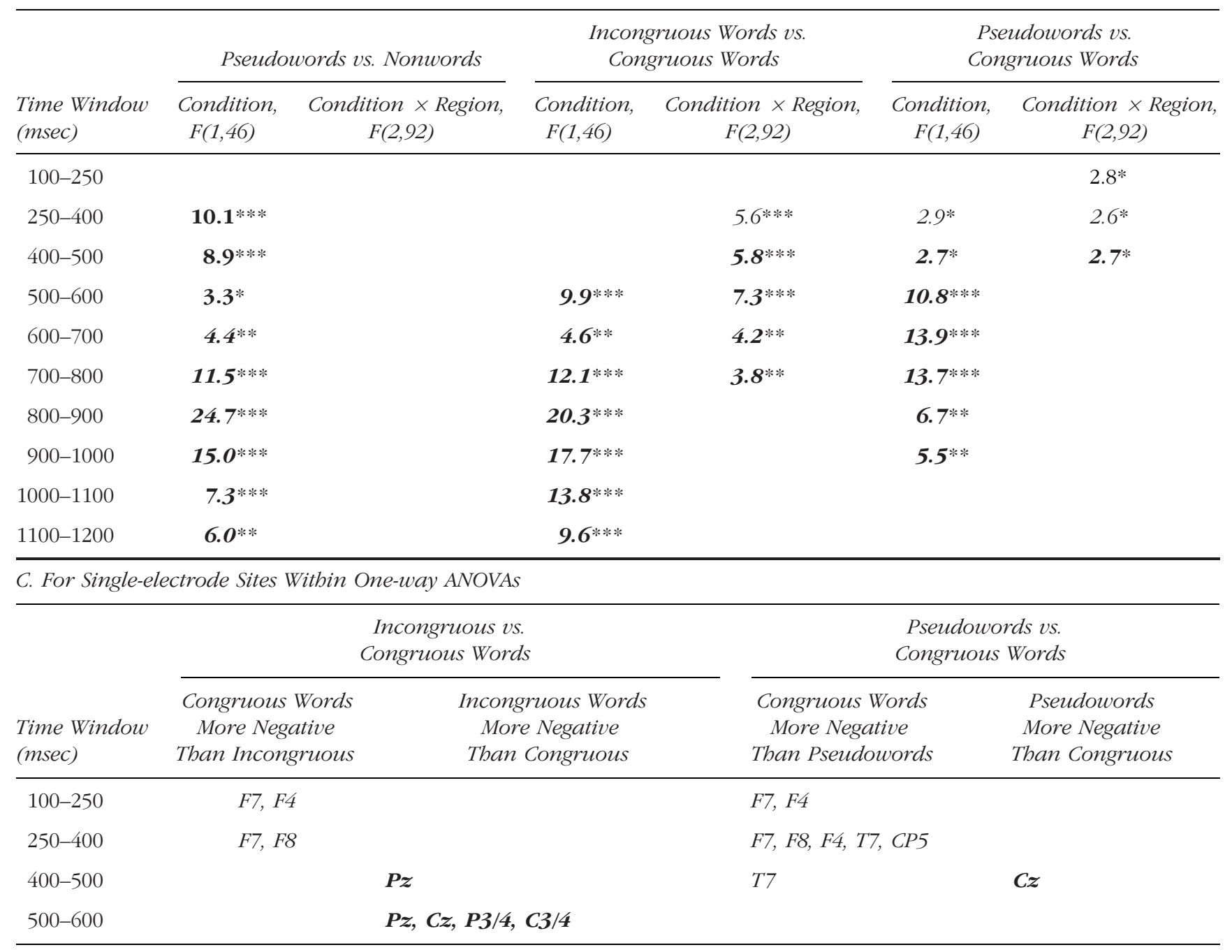


Table 2. (continued)

\begin{tabular}{|c|c|c|c|c|}
\hline \multirow[b]{2}{*}{$\begin{array}{l}\text { Time Window } \\
\text { (msec) }\end{array}$} & \multicolumn{2}{|r|}{$\begin{array}{l}\text { Incongruous vs. } \\
\text { Congruous Words }\end{array}$} & \multicolumn{2}{|c|}{$\begin{array}{l}\text { Pseudowords vs. } \\
\text { Congruous Words }\end{array}$} \\
\hline & $\begin{array}{l}\text { Congruous Words } \\
\text { More Negative } \\
\text { Than Incongruous }\end{array}$ & $\begin{array}{c}\text { Incongruous Words } \\
\text { More Negative } \\
\text { Than Congruous }\end{array}$ & $\begin{array}{l}\text { Congruous Words } \\
\text { More Negative } \\
\text { Than Pseudowords }\end{array}$ & $\begin{array}{c}\text { Pseudowords } \\
\text { More Negative } \\
\text { Than Congruous }\end{array}$ \\
\hline $600-700$ & & $P z, P 4, C 3 / 4, C P 6$ & & \\
\hline $700-800$ & & $P z, C z, P 3 / 4, C P 6, C 3 / 4, F C 3 / 4, F 3$ & & $P z, C z, F z$ \\
\hline $800-900$ & & $\begin{array}{l}P z, C z, F z, P 3 / 4, C 3 / 4, C P 5 / 6, \\
F C 3 / 4, F 3 / 4\end{array}$ & & $\begin{array}{l}P z, C z, F z, P 4, F C 3, \\
F 3 / 4\end{array}$ \\
\hline $900-1000$ & & $\begin{array}{l}P z, C z, F z, P 3 / 4, C 3 / 4, C P 5 / 6, \\
F C 3 / 4, F 3 / 4\end{array}$ & & $\begin{array}{c}P z, C z, F z, C 4, P 3 / 4 \\
F C 3 / 4, F 3 / 4, C P 6\end{array}$ \\
\hline $1000-1100$ & & $\begin{array}{l}P z, C z, F z, P 3 / 4, C 3 / 4, C P 6, F C 3 / 4 \\
F 3 / 4, T 8\end{array}$ & & $P z, P 3 / 4$ \\
\hline $1100-1200$ & & $P z, C z, F z, P 4, C 4, C P 6, F C 3 / 4, F 3 / 4$ & & $P z, P 3 / 4, T 7$ \\
\hline
\end{tabular}

Data in boldface represent phonotactic familiarity effect; in italics, lexical priming effect; in boldface italics, N400 semantic effect.

Data inside square brackets indicate Condition $\times$ Hemisphere, $F(1,46)$; in parentheses, Condition $\times$ Hemisphere $\times$ Region, $F(6,276)$, instead of Condition $\times$ Region.

$* p<.1$.

$* * p<.05$.

$* * * p<.01$

effect. In addition, interactions of condition with hemisphere were present from 700 to 1200 msec (Table 3A). Analyses of the hemispheres (Table 3C) indicated that the processing difference between incongruous and congruous words was larger over the right than over the left hemisphere (see Figure 6, right, top, for the spatial distribution).

\section{Pseudowords versus Congruous Words}

Similar to the comparison of incongruous and congruous words, early differences were also present between pseudowords and congruous words (Figure 5, right). They resulted in an interaction of condition with hemisphere from 100 to $250 \mathrm{msec}$ (Table 3A). Within this early time range, congruous words produced more negative responses than pseudowords over the left temporal brain region $[F(1,19)=19.2, p<.0005]$. At midline, a condition main effect with pseudowords being more negative than congruous words occurred as early as 250 to $400 \mathrm{msec}$ (Table 3B). Interactions of condition with region were observed during all time windows from 250 to $1200 \mathrm{msec}$. Analyses of singleelectrode sites revealed that pseudowords elicited more negative responses than congruous words in all except left temporal brain regions from 500 to $600 \mathrm{msec}$ and in all except left temporal and lateral frontal regions from 600 to $700 \mathrm{msec}$. From 700 to $1200 \mathrm{msec}$, all regions were involved in this effect, which again was reflected in condition main effects that were present from 500 to
1200 msec (see Figure 6, right, bottom, for the spatial distribution).

\section{DISCUSSION}

The present study was designed to investigate the sensitivity to phonotactic knowledge in 1-year-olds and to explore how this knowledge interacts with the development of lexical-semantic processing mechanisms. In particular, we wanted to examine whether N400-like mechanisms of semantic integration have already matured at the end of a child's first year of life and whether these mechanisms are activated by nonsense words varying in the dimension of phonotactic legality. Table 4 provides an overview of the observed ERP effects.

\section{Lexical Priming and Phonotactic Familiarity in 12-month-olds}

In the group of 12-month-old children, an N400 between incongruous and congruous words could not be observed. One possible interpretation is that the absence of the $\mathrm{N} 400$ is because children at that age do not comprehend the meaning of the presented words. However, during very early processing stages, congruous words elicited more negative responses than incongruous words, particularly over frontal, lateral frontal, and temporal brain regions. As the same words were 


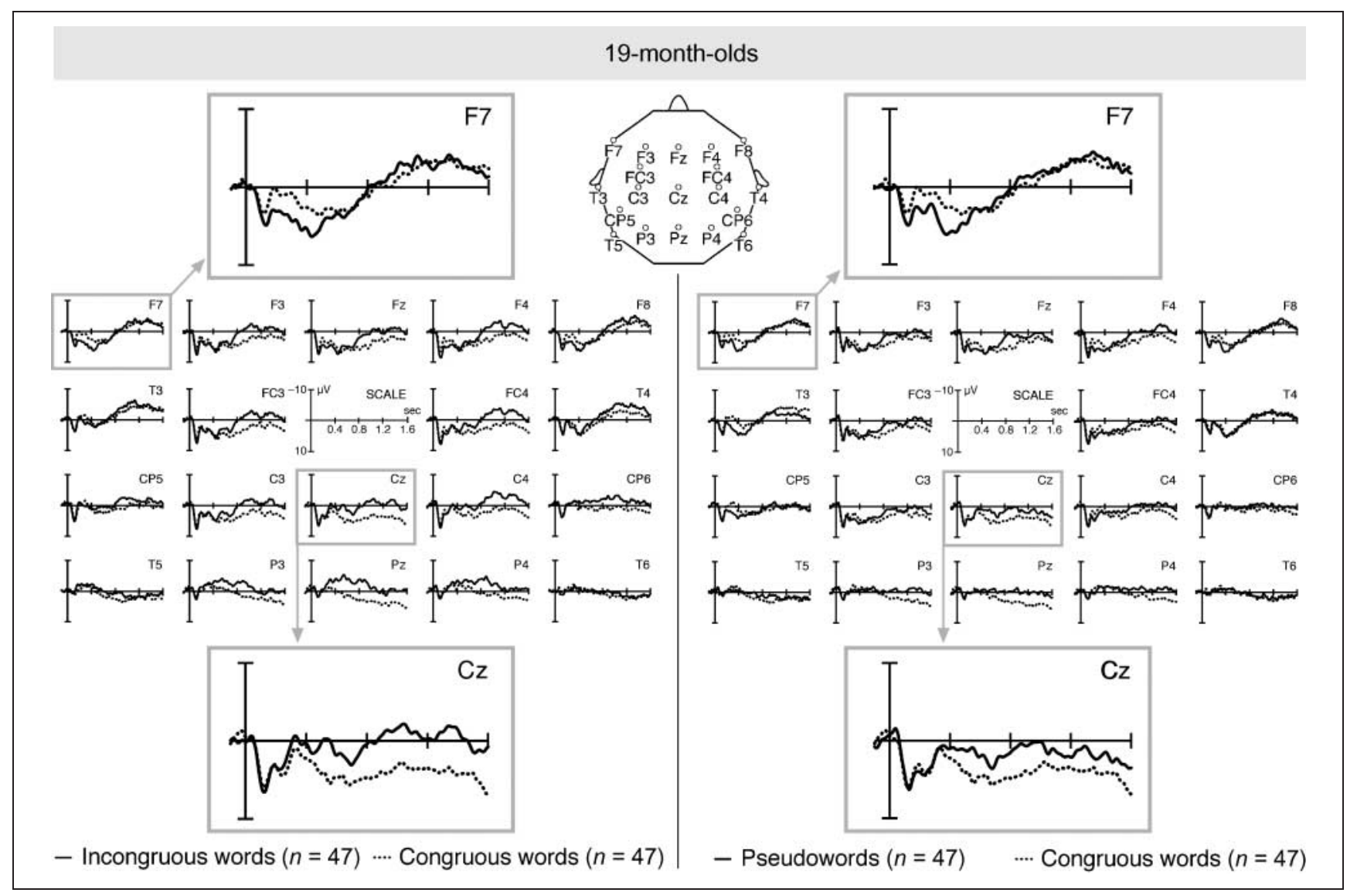

Figure 4. Comparison of the ERPs of 19-month-old children on incongruous and congruous words (left) and on pseudo- and congruous words (right).

presented in congruous and incongruous conditions, this processing difference must originate from the influence of a picture context on the expectation of a lexical element. From this lexical priming effect, we reason that the 12-month-old children in the present study already had some lexical-semantic knowledge about the presented words. This, in turn, suggest that either the N400 mechanisms generally or at least the mechanisms of its reduction by semantically primed congruous words are not yet matured at that age.

Children as young as 12 months of age already displayed differences between the processing of phonotactically legal pseudowords and nonwords with phonotactically illegal word onsets. These differences primarily occurred in left frontal brain region, and they were not present over centro-parietal regions. Both the spatial distribution of this effect and the missing N400 difference between incongruous and congruous words suggest that this phonotactic familiarity effect does not represent an N400-like response. Rather, it probably represents the facilitated acoustic-phonological processing of phonotactically legal phoneme clusters that the children have perceived previously in real word contexts and for which they have already established representations in their memory.
This interpretation is supported by the comparison of the responses on pseudo- and congruous words, which also did not reveal an enhanced N400-like negativity for pseudowords. During early processing stages, however, congruous words evoked more negative responses than pseudowords. As similar to incongruous words, in pseudowords, the first phonemes always differed from those of congruous words, this early effect is also caused by the lexical priming of congruous words (i.e., by facilitated acoustic-phonological processing of expected phonemes). In contrast to the difference between congruous and incongruous words, the effect between congruous and pseudowords persisted over a much longer period, and it also involved the centro-parietal brain region. This additional, more negative response to congruous than to pseudowords can be attributed to the children's lexical familiarity with words, because this part of the effect was neither present between known congruous and known incongruous words nor did it occur between unknown pseudo- and unknown nonwords. Because of strengthened memory representations, lexical familiarity could additionally facilitate the acousticphonological processing of known words. However, because the parietal brain region was mainly involved 


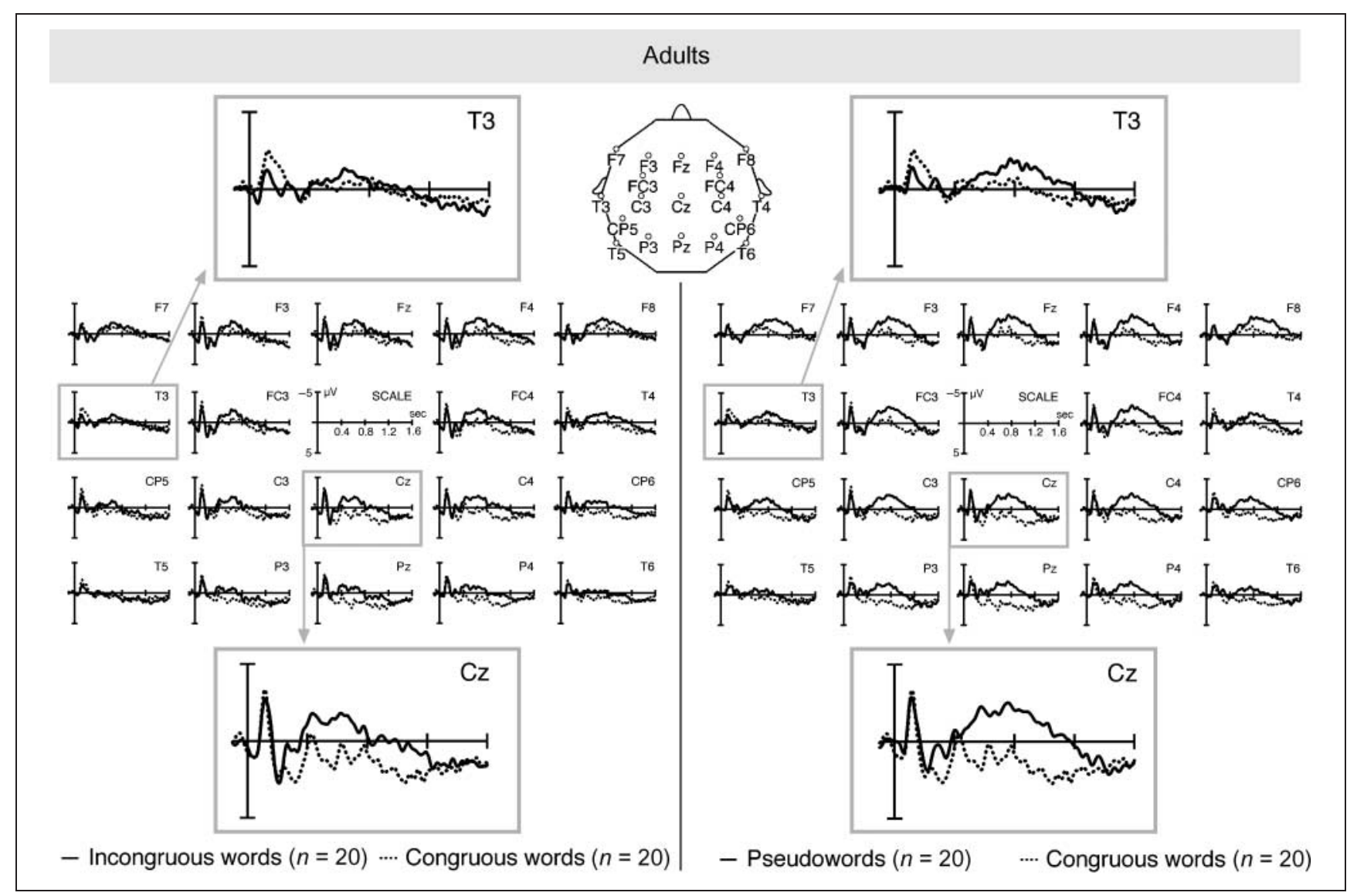

Figure 5. Comparison of the ERPs of adults on incongruous and congruous words (left) and on pseudo- and congruous words (right).

in the lexical familiarity effect, it might also represent an N400-like negativity that initially develops as a default response to known, but not to unknown, words and that is not yet reduced by semantic priming during its early stage of development.

\section{N400, Lexical Priming, and Phonotactic Familiarity in 19-month-olds}

As expected from our previous results (Friedrich \& Friederici, 2004), children at an age of 19 months displayed a broadly distributed, long-lasting negative wave in their ERPs when they processed words that were incongruous to pictures presented in a crossmodal priming paradigm. In the present analyses, this negativity started at about $400 \mathrm{msec}$ over the centroparietal brain region and spread out to more anterior regions during later periods. This effect is interpreted as an N400 semantic incongruity effect. ${ }^{1}$ The N400 in 19-month-olds was preceded by a lexical priming effect (i.e., more negative responses to congruous words) over lateral frontal brain regions, which are assumed to reflect reduced effort in the acoustic-phonological processing of expected congruous words.

The group of 19-month-old children, moreover, displayed processing differences between pseudo- and nonwords that started at about $250 \mathrm{msec}$ in the left frontal brain region and included widespread regions from about 400 to $1200 \mathrm{msec}$. The early onset of this effect and the comparison of its spatio-temporal distribution with that of the N400 semantic incongruity effect suggested that it is composed of a centro-parietal N400-like response on pseudowords and an earlier starting left frontal effect that is similar to the phonotactic familiarity effect observed in 12-month-old children. This interpretation was confirmed by the comparison of pseudo- and congruous words, which revealed a centro-parietal $\mathrm{N} 400$ on pseudowords from 500 to $1200 \mathrm{msec}$ in addition to the earlier occurring lexical priming effect on congruous words. The later onset of the N400 on pseudowords as compared to incongruous words and its reduced amplitude, especially over parietal brain regions, might be caused by the enhanced effort in processing unknown pseudowords. Thus, lexical familiarity that has already been assumed to cause a parietal negativity in 12-month-olds seems to affect the morphology of the N400 in 19-month-old children.

\section{N400 and Lexical Priming in Adults}

The long-lasting negative semantic incongruity effect in adults, with its centro-parietal focus and stronger effects over the right than the left hemisphere, clearly 
Table 3. Condition Effects of Adults

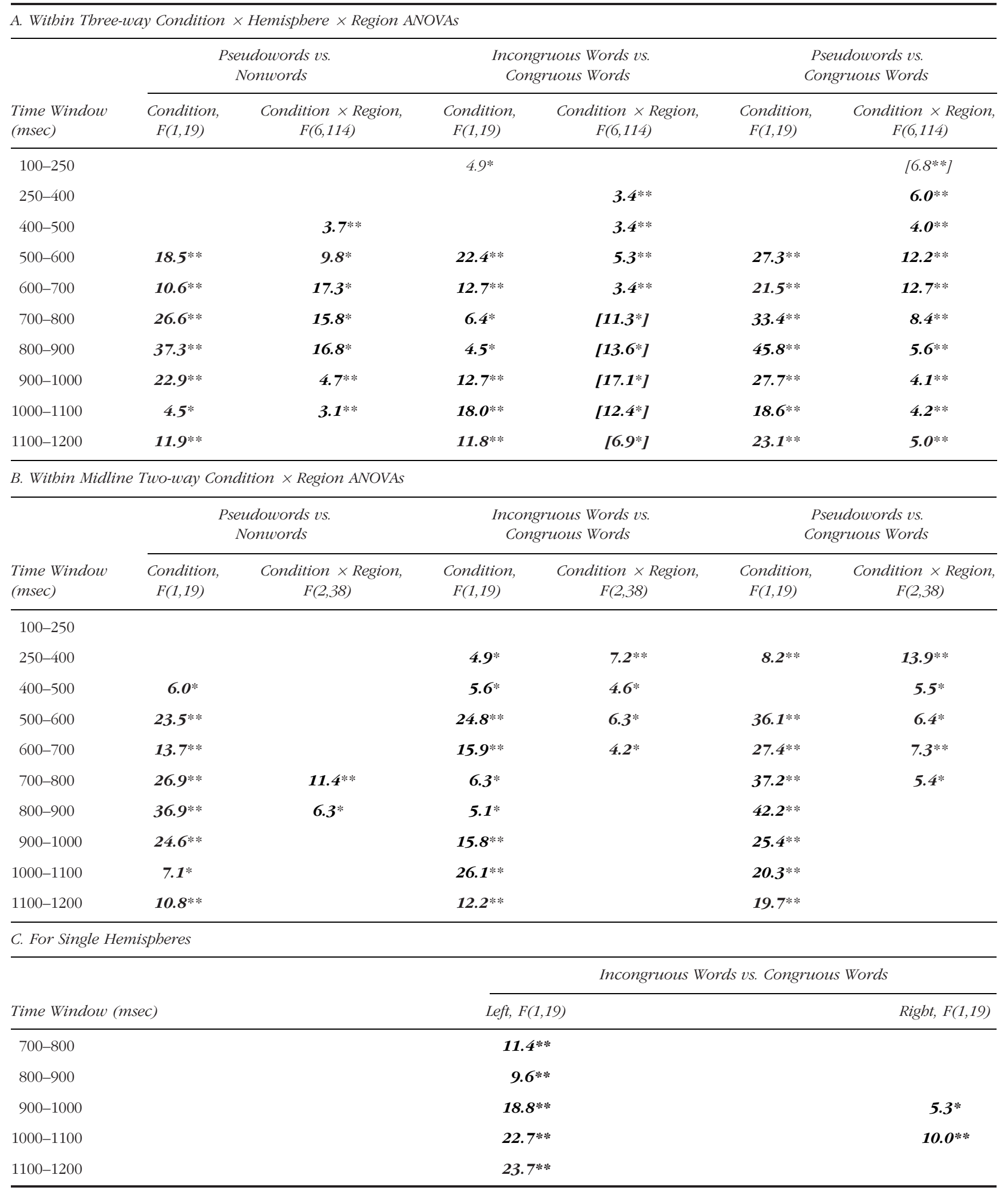

Data in italics represent lexical priming effect; in boldface italics, N400 semantic effect.

Data inside square brackets indicate Condition $\times$ Hemisphere, $F(1,19)$, instead of Condition $\times$ Region.

$* p<.05$.

$* * p<.01$. 


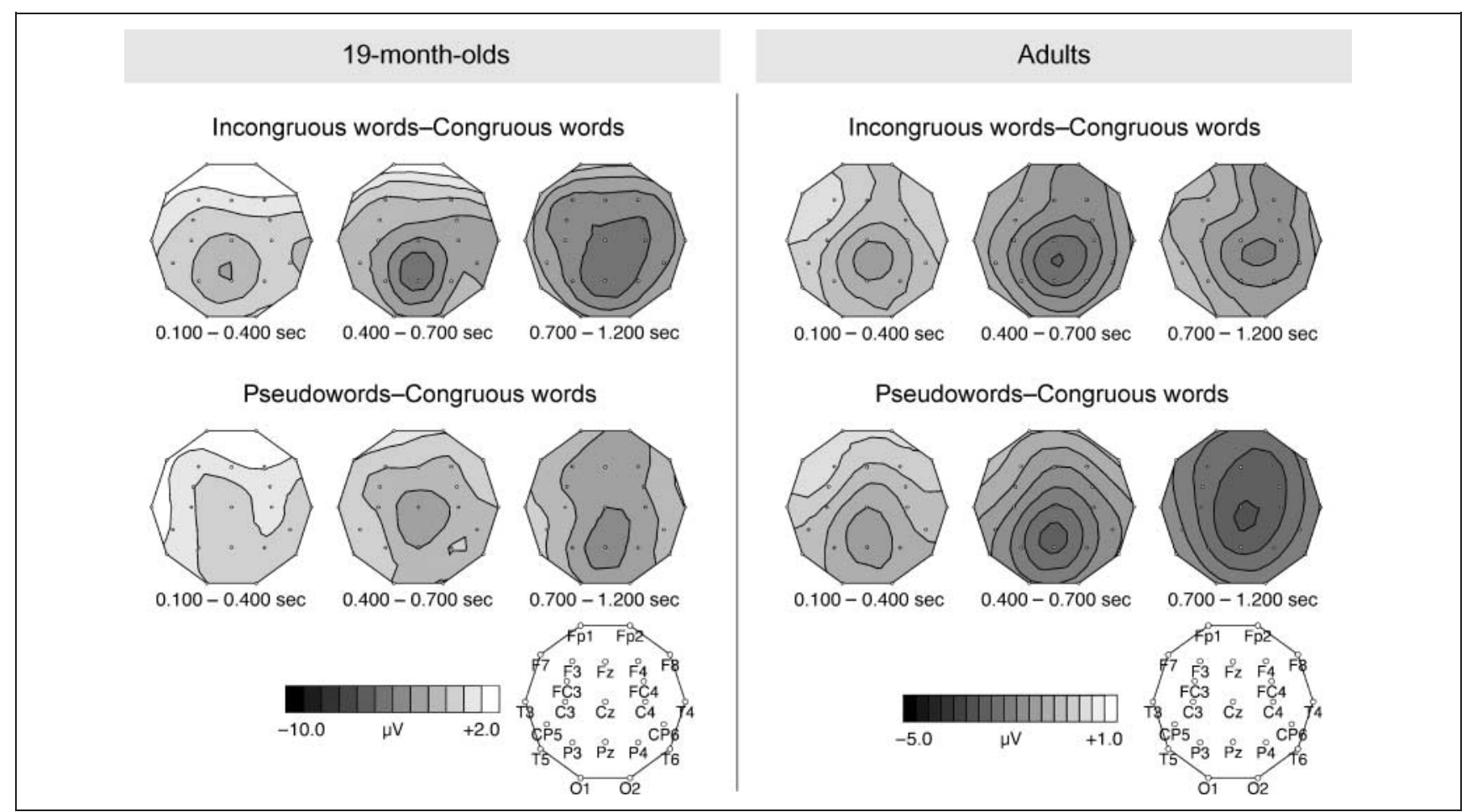

Figure 6. Spatial distribution of the difference between incongruous and congruous words and between pseudo- and congruous words in 19-month-olds (left) and in adults (right).

represents an N400 generally observed in semantic priming paradigms. It already started at about $250 \mathrm{msec}$ and had a similar morphology when comparing pseudowords and congruous words. The N400 was also present in the difference between pseudo- and nonwords, but slightly delayed as compared to the difference between pseudo- and congruous words. The early onset of the effect in the comparisons including congruous words was mainly caused by a centro-parietal positivity on these stimuli, which had a maximum at about 300 msec. It may represent a P300 that reflects the incidence of an expected event (Verleger, 1988) such as the occurrence of a basic-level word that named the presented picture. Alternatively, the early part of the N400 difference can be interpreted as a phonological N400 (i.e., the reduction of an N400 in response to the first phonemes of semantically primed congruous words) (Bentin et al., 1999). This effect was preceded by an early lexical priming effect in the left temporal brain region, which occurred with the same polarity and in the same temporal range as it started in 1-year-olds.

Different from the responses in 1-year-olds, adults did not display early differences between pseudo- and nonwords. The lack of these differences suggest that during early processing stages, phonotactically legal and illegal nonsense words were processed in a similar way although they differed in their physical features. The absence of a phonotactic familiarity effect in adults may be because adults commonly have some acoustic experi- ence with foreign languages. Moreover, the phonotactically illegal phoneme clusters of nonwords are built from phonemes of the adults' native language. These phonemes are highly automatized and have very well established memory representations so that they are easily processed even in phonotactically illegal combinations.

\section{General Discussion}

Early negative responses in the frontal and temporal brain regions of children under 2 years have previously been shown to differentiate the processing of known and unknown words, familiar and unfamiliar words, as well as words that differed in their initial phoneme (Thierry, Vihman, \& Roberts, 2003; Mills et al., 1993, 2004). Thierry et al. (2003), testing children's sensitivity to familiar and unfamiliar words out of context, found a negativity between 170 and $240 \mathrm{msec}$ to modulate as a function of familiarity in 11-month-olds. In 14-month-old children, the averaged negativity in the $200-$ to $400-\mathrm{msec}$ range differentiated between known and unknown words, but not yet between known words and those that differed in their initial phoneme. In 20-month-olds, this negativity also differentiated between known and the phonemic contrast words (Mills et al., 2004). In Mills et al.'s (1993) study with 20-month-olds, both the N200, defined as the most negative deflection between 125 and $250 \mathrm{msec}$, and the N350, defined as the strongest negativity between 275 and $450 \mathrm{msec}$, were larger to 
Table 4. Summary of the Observed ERP Effects

\begin{tabular}{|c|c|c|c|}
\hline & $\begin{array}{l}\text { 12-month- } \\
\text { olds }\end{array}$ & $\begin{array}{l}\text { 19-month- } \\
\text { olds }\end{array}$ & Adults \\
\hline \multicolumn{4}{|l|}{ Pseudowords vs. Nonwords } \\
\hline $\begin{array}{l}\text { Frontal negativity } \\
\text { for pseudowords } \\
\text { (phonotactic } \\
\text { familiarity effect) }\end{array}$ & + & + & - \\
\hline $\begin{array}{l}\text { N400 for pseudowords } \\
\text { (semantic processes } \\
\text { triggered) }\end{array}$ & - & + & + \\
\hline \multicolumn{4}{|c|}{ Incongruous Words vs. Congruous Words } \\
\hline $\begin{array}{l}\text { Early negativity for } \\
\text { congruous } \\
\text { words (lexical } \\
\text { priming effect) }\end{array}$ & + & + & + \\
\hline $\begin{array}{l}\text { N400 for incongruous } \\
\text { words (semantic } \\
\text { integration effect) }\end{array}$ & - & + & + \\
\hline \multicolumn{4}{|c|}{ Pseudowords vs. Congruous Words } \\
\hline $\begin{array}{l}\text { Early negativity for } \\
\text { congruous words } \\
\text { (lexical priming effect) }\end{array}$ & + & + & + \\
\hline $\begin{array}{l}\text { N400 for pseudowords } \\
\text { (semantic processes } \\
\text { triggered) }\end{array}$ & - & + & + \\
\hline
\end{tabular}

known than to unknown words, and absent or strongly attenuated to backward-presented words. In the 19-month-olds of the present study, the negative responses within 250 to $400 \mathrm{msec}$ differed as a function of phonotactic familiarity. Like the difference between unknown and backward words in Mills et al.'s study, the negativity on nonwords was strongly attenuated as compared to pseudowords. In the earlier time range from 100 to $250 \mathrm{msec}$, however, the responses between pseudo- and nonwords did not differ. These somewhat different responses on nonwords in our study and backward-presented words in Mills et al.'s study appear to reflect the fact that we used naturally spoken nonwords that meet phonetic and prosodic properties of German and, at the second phoneme, violate only phonotactic regularities. Backward-presented words, however, violate not only phonotactic but also phonetic and prosodic features of a language, and these violations already occur at the word onset.

In Mills et al.'s $(1993,2004)$ and Thierry et al.'s (2003) studies as well as in the present study, amplitudes of the early frontal and temporal negative components appear to reflect familiarity with native language stimuli that enhances efficiency in acoustic-phonological pro- cessing. In the present study, in both 12- and 19-monthold children, the response between 100 and 400 msec differed as a function of lexical priming even for identical word stimuli. Thus, similar to strengthened memory representations of familiar words or familiar phonotactic features, mechanisms of lexical priming are also able to facilitate the acoustic-phonological processing of words in 1-year-olds. Because in the present study, the lexical priming already affected the first phoneme and phonotactic violations only occurred at the second phoneme, the phonotactic familiarity effect had a longer latency than the lexical priming effect.

The occurrence of an N400 on pseudowords, but not on nonwords, in adults replicates previous findings that semantic processing is triggered in response to pseudowords, not to nonwords (e.g., Bentin et al., 1999; Nobre \& McCarthy, 1994; Holcomb \& Neville, 1990). These findings were obtained by using either visually presented stimuli or acoustically presented backward speech for the nonword condition. The result of the present study goes beyond these studies, though, as it shows that the violation of only phonotactic properties in naturally spoken nonsense words is sufficient to suppress the initiation of semantic mechanisms that are indexed by the N400. Thus, phonotactic properties are essential for the distinction of naturally spoken pseudo- and nonwords.

The N400 difference between pseudo- and nonwords in 19-month-olds indicates the presence of semantic processing differences between nonsense words with phonotactically legal and illegal word onset at that age. The missing $\mathrm{N} 400$ on nonwords implies that phonotactically illegal nonsense words are not semantically processed, whereas the presence of an N400 on pseudowords indicates that semantic mechanisms are triggered in response to legal nonsense words. This result suggests that 19-month-old children take legal, but not phonotactically illegal, nonsense words for potential words, and thus they regard only pseudowords as potential referents for meaning.

The absence of an N400 in 12-month-olds might suggest that children at that age are not sensitive to phonotactic regularities. The occurrence of a phonotactic familiarity effect in the left fronto-lateral brain region, however, indicates that 12-month-olds are more familiar with the phonotactically legal word onsets of pseudowords than with the phonotactically illegal word onsets of nonwords. This different processing of pseudo- and nonwords suggests the existence of some implicit phonotactic knowledge at the age of 12 months. This result is in line with behavioral studies that have shown that even 9-month-olds are sensitive to the phonotactic structure of word boundaries (Mattys \& Jusczyk, 2000; Friederici \& Wessels, 1993). The finding that in 12-month-olds the N400 did not occur in response to any nonsense word (i.e., neither on pseudo- nor on nonwords) could have two possible reasons: either the 
N400 is missing because the mechanisms that it reflects are not yet matured at that age, or the N400 mechanisms are already present but not triggered by nonsense words. Given that in this age group an N400 difference between incongruous and congruous words did not occur, eventhough the lexical priming effect indicated the presence of some lexical-semantic knowledge, it seems that the N400 is generally absent. However, negative differences between congruous and pseudowords that were observed over the parietal brain region in the N400 time range could have been caused by an N400 that already occurs in response to known, but not to unknown, words. In either case, the N400 appears to develop only in response to potential words at a time when native language regularities have already been acquired. This is in contrast to the view that the $\mathrm{N} 400$ is already present at birth and declines in response to nonwords during the acquisition of native language regularities.

\section{Conclusion}

The occurrence of phonotactic familiarity and lexical priming effects in 12- and 19-month-old children indicates that both their early experience with phonotactic regularities of their native language and their lexicalsemantic knowledge already affect the acoustic-phonological processing of words or word-like stimuli. Mechanisms of semantic integration indexed by the N400, or at least the mechanisms of N400 reduction by semantic priming, were not observed in 12-month-olds. In 19-month-olds, the occurrence of an N400 depends on the regularity of phonotactic features of nonsense words. Like in adults, in this age group, an N400 occurred on incongruous as well as on pseudowords. Although for congruous words, the N400 was attenuated by semantic priming, semantic processing mechanisms were not triggered in response to phonotactically illegal nonwords. This indicates that at an age of 19 months, phonotactically legal pseudowords, but not phonotactically illegal nonwords, are considered as potential words. How such rule-like behavior develops from the children's sensitivity to phonotactic probabilities is still a topic for further research.

\section{METHODS}

\section{Participants}

The present study was part of the German Language Development Study. Families participate in the study according to institutional signed informed consent procedures. For participation in the study, full-term infants were chosen by pediatricians based on a normal course of pregnancy and normal birth. They were healthy and without neurological or developmental problems. Only children with monolingual experience with German participate in the GLaD study. Children with a family history of a developmental language disorder were excluded from the present analyses.

A total of 20 adults (mean age 23.7 years, 10 men and 10 women) were measured. Children of the older age group were recorded when they were 19 months old ( \pm 7 days). In the younger age group, recordings were taken when the children were 12 months old ( \pm 7 days). During electroencephalographic (EEG) recordings, the children's behavior was continuously observed via a video monitor to determine whether they were looking at the pictures. In the analyses presented here, we included only those children who were looking at the pictures in at least $70 \%$ of the trials and met the criteria of 20 artifact-free trials per condition. A total of 46 children at the age of 12 months ( 27 boys and 19 girls) and 47 children at the age of 19 months (26 boys and 21 girls) entered the final analyses. On average, these children were looking at the monitor during about 83\% of the whole session. Because of technical restrictions, we also included trials of the remaining $17 \%$ in the average. However, because the unattended trials were often accompanied with motor movement, most of these trials were excluded as artifacts.

\section{Procedure}

During the EEG recordings, participants were seated in front of a TFT-LCD computer screen (distance about 1$1.5 \mathrm{~m}$ ) in a dimly lit, electrically shielded, and sound insulated experimental room. The total experimental session lasted about $12 \mathrm{~min}$. It was divided into two blocks with a short break between the blocks.

At each trial, a colored picture of a single object appeared for $4000 \mathrm{msec}$ on the screen. After an interval of $900 \mathrm{msec}$ from picture onset, a German indefinite article with a word length of about $700 \mathrm{msec}$ was acoustically presented to refer to the pictured object in a natural way and to increase the children's attention. After a natural pause of about 300 msec, while the picture was still seen on the screen, the article was followed by a word, a pseudoword, or a nonword. Words, pseudo-, and nonwords were mixed within each block.

\section{Stimuli}

The visual stimulus material used in the present study was especially developed to be suitable for 1-year-old children. That is, pictures were simple colored illustrations that are clearly identifiable. They were selected in such a way that the children already knew most of them. The acoustic stimuli were 44 basic level words and 44 mono- and bisyllabic nonsense words. They were very slowly spoken by a young woman, digitized at a rate of 44,100 Hz, and presented via loudspeaker with an intensity of approximately $65 \mathrm{~dB}$ SPL. 
Words were either correct basic level names of the pictured objects or basic level names of other objects (i.e., either congruous or incongruous to the picture meanings). For 19-month-olds, the results of the word conditions were already reported by Friedrich and Friederici (2004). Here, the word conditions were taken as a control to compare the effects of nonsense words with those of words within exactly the same children groups. Both incongruous as well as nonsense words always differed in their first phoneme from the congruous words presented with the same pictures. Nonsense words were either pseudo- or nonwords. Pseudowords were phonotactically legal in German (e.g., fless or traune). Nonwords had a word onset that is phonotactically illegal in German (e.g., rlink or sranto). Information about the phonotactic irregularity of nonwords was available at the second phoneme, on average, $174 \mathrm{msec}$ after word onset. Mean word length was 1083 msec for words, $1084 \mathrm{msec}$ for pseudowords, and $1085 \mathrm{msec}$ for nonwords.

Each acoustic stimulus was presented two times. Each picture was presented four times, once with a congruous word, once with an incongruous word, once with a pseudoword, and once with a nonword to ensure that the effect of the visual stimuli was the same in each condition. For the presentation, a fixed randomization was created in which there was no obvious semantic relation between an object and its incongruous word, between an object and a word that is phonologically similar to the nonsense word (e.g., a rhyming word), or between immediately following item pairs.

\section{Event-related Brain Potential Recording and Averaging}

The EEG was continuously recorded from silver-silver chloride electrodes at sites F7, F3, Fz, F4, F8, FC3, FC4, T3, C3, C4, T4, CP5, CP6, T5, P3, Pz, P4, T6, O1, and O2 as well as at left and right mastoids (according to the 10-20 International System of Electrode Placement) attached to an elastic electrode cap (Easy Cap, Falk Minow Services, Herrsching Breitbrunn, Germany). During the recordings, the ERP electrodes were referenced to $\mathrm{Cz}$. Electrooculogram (EOG) electrodes were recorded bipolar. Electrode impedances were below $5 \mathrm{k} \Omega$ for adults and, for children, mostly below $10 \mathrm{k} \Omega$ and at least below $20 \mathrm{k} \Omega$. The EEG was amplified with PORTI-32/ MREFA (Twente Medical Systems, with input impedance of $10^{12} \Omega$ and analogue first-order low-pass filter of $5 \mathrm{kHz}$ ), digitized on-line at a rate of $500 \mathrm{~Hz}$ (AD converter with 22 bit, digital filter from DC to $125 \mathrm{~Hz}$ ), and stored on hard disk. Further analyses were processed off-line.

The EEG was algebraically re-referenced to the average of left and right mastoids (A1 and A2). A zero-phase digital band-pass filter ranging from 0.3 to $20 \mathrm{~Hz}(-3 \mathrm{~dB}$ cutoff frequencies of 0.43 and $19.87 \mathrm{~Hz}$ ) was applied to increase the signal-to-noise ratio by removing slow drifts and muscle artifacts. All trials were individually checked for artifacts. Blinks and horizontal eye movements were corrected by a computer algorithm. All other artifacts were rejected manually. Epochs of $1600 \mathrm{msec}$ from word onset were averaged according to a $200-\mathrm{msec}$ prestimulus baseline. At least 20 artifact-free trials in each condition were required for an individual average to be included in further analyses. The mean number of accepted trials was 24 for 12-month-olds and 25 for 19-month-olds. These numbers did not differ between conditions.

\section{Data Analyses}

To investigate the early negative responses, mean amplitudes were calculated within two time windows from 100 to 250 and from 250 to $400 \mathrm{msec}$. From 400 to $1200 \mathrm{msec}$, mean amplitudes within consecutive time windows of 100-msec duration were analyzed.

To assess differences between conditions as well as the topological aspects of these differences, threeway analyses of variance (ANOVAs) with word condition (pseudo- vs. nonwords; incongruous vs. congruous words; pseudo- vs. congruous words), hemisphere (left, right), and region (lateral frontal $[\mathrm{F} 7 / 8]$, frontal $[\mathrm{F} 3 / 4]$, fronto-central $[\mathrm{FC} 3 / 4]$, temporal $[\mathrm{T} 3 / 4]$, central $[\mathrm{C} 3 / 4]$, centro-parietal $[\mathrm{CP} 5 / 6]$, and parietal $[\mathrm{P} 3 / 4])$ as within-subject factors were carried out for each group separately. For midline sites, two-way ANOVAs with word condition (pseudo- vs. nonwords; incongruous vs. congruous words; pseudo- vs. congruous words) and region (frontal, central, parietal) were performed. Significant interactions including the factor condition were analyzed by one-way ANOVAs for single-electrode sites. In all ANOVAs, the Greenhouse-Geisser correction (Greenhouse \& Geisser, 1959) was applied whenever there was more than one degree of freedom. Here, we report uncorrected degrees of freedom and adjusted $p$ values.

\section{Acknowledgments}

We thank all the families who took part in this study. Special thanks go to Christina Rügen and Jördis Haselow for their empathy in treating our subjects and their commitment in recording the ERP data. The data characterizing the developmental state of our subjects were kindly provided by Volker Hesse, head of the pediatric clinic of the Krankenhaus Lichtenberg, teaching hospital of the Charité, Berlin. He and his team took care of the somatic and neurological data of the children, and he provided resources and workforce for recruiting subjects. This study was supported by the Deutsche Forschungsgemeinschaft (German Research Foundation) (FR-519/18-1).

Reprint request should be sent to Manuela Friedrich, Max Planck Institute for Human Cognitive and Brain Sciences, P.O. 
Box 500 355, 04303 Leipzig, Germany, or via e-mail: friedri@ cbs.mpg.de.

\section{Note}

1. Note that differences in the N400 latency between the results of the present study and that of Friedrich and Friederici (2004) are because of both different subjects that met the inclusion criteria in the two studies and different methodological aspects. Particularly, in the present study, the signal-to-noise ratio was increased by manual rejections and EOG compensation.

\section{REFERENCES}

Bentin, S. (1987). Event-related potentials, semantic processes, and expectancy factors in word recognition. Brain and Language, 31, 308-327.

Bentin, S., McCarthy, G., \& Wood, C. C. (1985). Event-related potentials, lexical decision and semantic priming. Electroencephalography and Clinical Neurophysiology, 60, 343-355.

Bentin, S., Mouchetant-Rostaing, Y., Giard, M. H., Echallier, J. F., \& Pernier, J. (1999). ERP manifestation of processing printed words at different psycholinguistic levels: Time course and scalp distribution. Journal of Cognitive Neuroscience, 11, 235-260.

Best, C. T., McRoberts, G. W., \& Sithole, N. M. (1988). Examination of the perceptual re-organization for speech contrasts: Zulu click discrimination by English-speaking adults and infants. Journal of Experimental Psychology: Human Perception and Performance, 14, 245-360.

Cheour, M., Ceponiene, R., Lehtokoski, A., Luuk, A., Allik, J., Alho, K., \& Näätänen, R. (1998). Development of language-specific phoneme representations in the infant brain. Nature Neuroscience, 1, 351-353.

Coch, D., Maron, L., Wolf, M., \& Holcomb, P. J. (2002). Word and picture processing in children: An event-related potential study. Developmental Neuropsychology, 22, 373-406.

Friederici, A. D., \& Hahne, A. (2001). Developmental patterns of brain activity for semantic and syntactic processes. In B. Höhle \& J. Weissenborn (Eds.), Approaches to bootstrapping in early language development (pp. 231-246). Amsterdam: John Benjamins.

Friederici, A. D., Pfeifer, E., \& Hahne, A. (1993). Event-related brain potentials during natural speech processing: Effects of semantic, morphological and syntactic violations. Cognitive Brain Research, 1, 183-192.

Friederici, A. F., \& Wessels, J. M. I., (1993). Phonotactic knowledge of word boundaries and its use in infant speech perception. Perception and Psychophysics, 54, 287-295.

Friedman, D. Sutton, S., Putnam, L., Brown, \& ErlenmeyerKimling, L. (1988). ERP components in picture matching in children and adults. Psychophysiology, 25, 570-590.

Friedrich, M., \& Friederici, A. D. (2004). N400-like semantic incongruity effect in 19-month-olds: Processing known words in picture contexts. Journal of Cognitive Neuroscience, 16, 1465-1477.

Gonzalez-Garrido, A. A., Oropeza de Alba, J. L., Riestra Castaneda, R., Riestra Castaneda, J. M., Perez Avalos, M. C., \& Valdes Sosa, M. (1997). Event related brain potentials to semantically incongruent words in children of different ages. Archives of Medical Research, 28, 109-113.
Greenhouse, S. W., \& Geisser, S. (1959). On methods in the analysis of profile data. Psychometrika, 24, 95-112.

Hahne, A., Eckstein, K., \& Friederici, A. D. (2004). Brain signatures of syntactic and semantic processes during development. Journal of Cognitive Neuroscience, 16, 1302-1318.

Holcomb, P. J. (1993). Semantic priming and stimulus degradation: Implications for the role of the N400 in language processing. Psychophysiology, 30, 47-61.

Holcomb, P. J., Coffey, S. A., \& Neville, H. J. (1992). Visual and auditory sentence processing: A developmental analysis using event-related brain potentials. Developmental Neuropsychology, 8, 203-241.

Holcomb, P. J., \& Neville, H. J. (1990). Auditory and visual semantic priming in lexical decision: A comparison using event-related brain potentials. Language and Cognitive Processes, 5, 281-312.

Jusczyk, P. W. (1997). The discovery of spoken language Cambridge: MIT Press.

Jusczyk, P. W., Cutler, A., \& Redanz, N. J. (1993). Infant's sensitivity to the predominant stress pattern of English words. Child Development, 64, 675-687.

Jusczyk, P. W., Friederici, A. D., Wessels, J. M. I., Svenkerud, V. Y., \& Jusczyk, A. M. (1993). Infant's sensitivity to the sound patterns of native language words. Journal of Memory and Language, 32, 402-420.

Kuhl, P. K., Williams, K. A. Lacerda, F., Stevens, K. N., \& Lindblom, B. (1992). Linguistic experience alters phonetic perception in infants by 6 months of age. Science, 255, 608-608.

Kutas, M., \& Federmeier, K. D. (2000). Electrophysiology reveals semantic memory use in language comprehension. Trends in Cognitive Sciences, 4, 463-470.

Kutas, M., \& Hillyard, S. A. (1980). Reading senseless sentences: Brain potentials reflect semantic incongruity. Science, 207, 203-205.

Kutas, M., \& Van Petten (1994). Psycholinguistics electrified: Event-related brain potential investigations. In $\mathrm{M}$. Gernsbacher (Ed.), Handbook of psycholinguistics (pp. 83-143). New York: Academic Press.

Mattys, S. L., \& Jusczyk, P. W., (2000). Phonotactic cues for segmentation of fluent speech by infants. Cognition, 78, 91-121.

Mills, D. L., Coffey-Corina, S. A., \& Neville, H. J. (1993). Language acquisition and cerebral specialization in 20-month-old infants. Journal of Cognitive Neuroscience, 5, 317-334

Mills, D. L., Coffey-Corina, S. A., \& Neville, H. J. (1994). Variability in cerebral organization during primary language acquisition. In G. Dawson \& K. Fischer (Eds.), Human behavior and the developing brain (pp. 427-455). New York: Guilford Press.

Mills, D. L., Prat, C., Zangl, R., Stager, C. L., Neville, H. J., \& Werker, J. F. (2004). Language experience and the organization of brain activity to phonetically similar words: ERP evidence from 14- and 20-month-olds. Journal of Cognitive Neuroscience, 16, 1452-1464.

Molfese, D. L. (1989). Electrophysiological correlates of word meanings in 14-month-old human infants. Developmental Neuropsychology, 5, 79-103.

Molfese, D. L., (1990). Auditory evoked responses recorded from 16-month-old human infants to words they did and they did not know. Brain and Language, 38, 345-363.

Molfese, D. L., Wetzel, W. F., \& Gill, L. A. (1993). Known versus unknown word discrimination in 12-month-old human infants: Electrophysiological correlates. Developmental Neuropsychology, 3-4, 241-258. 
Nobre, A. C., \& McCarthy, G. (1994). Language related ERPs: Scalp distributions and modulation by word-type and semantic priming. Journal of Cognitive Neuroscience, 6, 233-255.

Rugg, M. D., \& Nagy, M. E. (1987). Lexical contribution to nonword-repetition effects: Evidence from event-related potentials. Memory and Cognition, 15, 473-481.

Thierry, G., Vihman, M., \& Roberts, M. (2003). Familiar words capture the attention of 11-month-olds in less than 250 ms. NeuroReport, 14, 2307-2310.

Verleger, R. (1988). Event-related potentials and cognition: A critique of the context-updating hypothesis and an alternative interpretation of the P3. Behavioral and Brain Sciences, 11, 343-427.

Werker, J. F., \& Lalonde, C. E. (1988). Cross-language speech perception: Initial capabilities and developmental change. Developmental Psychology, 24, 1-12.

Werker, J. F., \& Tees, R. C. (1984). Cross-language speech perception: Evidence for perceptual reorganization during the first year of life. Infant Behavior and Development, 7, 49-63.

West, W. C., \& Holcomb, P. J. (2002). Event-related potentials during discourse-level semantic integration of complex pictures. Cognitive Brain Research, 13, $363-375$. 